\title{
Preservar e resistir: padrões de alienação de imóveis no período babilônico antigo*
}

Marcelo Rede ${ }^{* *}$

As análises das atividades econômicas dos grupos domésticos da antiga Mesopotâmia concentraram-se, em grande parte, nos arquivos formados pelos compradores de imóveis. Por decorrência, no que diz respeito à circulação de bens imobiliários, foram privilegiadas as estratégias de aquisição dos terrenos. Neste artigo, buscamos estabelecer algumas tendências do comportamento de alienação por parte dos vendedores a partir de um estudo serial da documentação contratual da cidade-reino de Larsa durante os séculos XIX e XVIII a.C.

Palavras-chave: Mesopotâmia - Imóveis - Comportamento de Alienação

To Preserve and Resist: Patterns of Land Alienation in Ancient Babylon

Analysis of the economic activities of domestic groups in ancient Mesopotamia has generally relied upon archives belonging to real estate buyers. Buying strategies have therefore always been the privileged focus of understandings of the circulation of land within ancient Babylonian society. The present article tries to documents behavioral trends among land sellers, using a serial study of the known contracts from the city of Larsa during the XIX-XVIIIth B.C. as its main basis.

Keywords: Mesopotamia - Real Estate - Sellers' Behavior

* Artigo recebido em maio de 2006 e aprovado para publicação em agosto de 2006.

** Professor Adjunto da Universidade Federal Fluminense. Membro do núcleo de estudos CEIA.E-mail:mrede@uol.com.br. 
Préserver et résister: modèles d'aliénation de biens immeubles pendant la période Babylonienne ancienne

Les analyses des activités économiques des groupes domestiques de l'ancienne Mésopotamie ont surtout été consacrées aux archives rassemblées par les acheteurs de biens immeubles. Ainsi, la circulation immobilière a essentiellement été envisagée du point de vue des stratégies d'acquisition des terrains. Cet article vise à établir quelques tendances du comportement d'aliénation de la part des vendeurs. Pour cela, on a procédé à une étude sérielle des contrats de Larsa aux XIX ${ }^{e}$ et XVIII ${ }^{e}$ siècles av. J.-C.

Mots-clés: Mésopotamie - Biens Immeubles - Comportement d'Aliénation

Nos debates acerca da natureza da economia mesopotâmica, o problema da alienação das terras sempre ocupou um lugar de destaque. Na maior parte do tempo, a capacidade de alienação foi considerada um fator decisivo para apoiar ou negar a existência do controle dos bens fundiários por parte de indivíduos ou famílias. Assim, a discussão acerca da existência da "propriedade privada" proliferou - por vezes, com base em premissas bastante movediças - e monopolizou a atenção tanto de seus defensores como de seus detratores. De certo modo, demonstrar a presença ou ausência deste único fator parecia ser suficiente para estabelecer a natureza de todo o sistema econômico. ${ }^{1}$

Desde as primeiras publicações de textos cuneiformes, a partir da segunda metade do século XIX, as evidências documentais mostravam que a alienação da terra - mas de espaços seletivos, que, em muitos casos, excluíam justamente os campos agrícolas e limitavam-se a pequenos terrenos urbanos, casas, pomares - foi uma possibilidade efetiva, embora sempre cercada de resistências mentais e de restrições concretas ou mesmo legais. Se a documentação do terceiro milênio é de difícil interpretação e não permite ver com clareza os detalhes e a dimensão socioeconômica do processo de transferência

\footnotetext{
${ }^{1}$ Para uma visão geral do debate acerca da natureza da economia mesopotâmica, ver, de um lado, os trabalhos de J. Renger, "On economic structures in ancient Mesopotâmia”, Orientalia, 1994, p. 157-208, e "Institutional, communal, and individual ownership or possession of arable land in ancient Mesopotamia from the end of the fourth to the end of the first millennium B.C.", Chicago-Kent Law Review, 71, 1995, p. 269-319, e, de outro, M. Silver, Economic structures of antiquity, Westport/London, Greenwood Press, 1995, que representam posições diametralmente opostas; para uma síntese, ver M. Van De Mieroop, "Economic History", Cuneiform texts and the writing of history, London, Routledge, 1999.
} 
de terras a que ela parece aludir, ${ }^{2}$ os primeiros séculos do segundo milênio viram, sem contestação possível, a multiplicação dos contratos de alienação imobiliária firmados entre indivíduos ou grupos. No entanto, tais evidências não apontam necessariamente, como muitos quiseram fazer crer, para um primado da propriedade privada, em detrimento de outras formas de controle

\footnotetext{
$\overline{{ }^{2} \text { A bibliografia sobre a questão do controle das terras durante o terceiro milênio é vasta: ver, }}$ sobretudo, a publicação e o comentário histórico das primeiras estelas mesopotâmicas tratando de transferências de terras em I. J. Gelb, P. Steinkeller e R. M. Whiting, Earliest land tenure systems in the Near East: the ancient kudurrus (Oriental Institute Publications, 104), Chicago, The Oriental Institute of the University of Chicago, 1991. Ver igualmente J.-P. Gregoire, "L'origine et développement de la civilisation Mésopotamienne du troisième millénaire avant notre ère", C. H. Breteau et alii, Production, pouvoir et parenté dans le monde méditerranéen, Paris, Geuthner, 1981, p. 27-101; J.-J. Glassner, "Aspects du don, de l'échange et de l'appropriation du sol dans la Mésopotamie du IIIe Millénaire, avant la fondation de l'empire d'Ur", Journal Asiatique, 273, 1985, p. 11-59, e "La gestion de la terre en Mésopotamie selon le témoignage des kudurrus anciens", Bibliotheca Orientalis, 52, 1995, p. 5-24; M. A. Powell, "Elusive Eden: private property at the dawn of history", Journal of Cuneiform Studies, 46, 1994, p. 99-104; H. Neumann, "Zum Problem des privaten Bodeneigentums in Mesopotamien (3. Jt. v. u. Z.)", in B. Brentjes (ed.), Das Grundeigentum in Mesopotamien (Jahrbuch für Wirtschafts Geschichte), Berlin, Akademie Verlag, 1988, p. 29-48; D. O. Edzard, "Private land ownership and its relation to 'God' and the 'State' in Sumer and Akkad", in M. Hudson e B. A. Levine (eds.), Privatization in the ancient Near East and Classical World (Peabody Museum Bulletin, 5). Cambridge, MA: Peabody Museum of Archaeology and Ethnology, 1996, p. 109-128; G. Buccellati, "The role of socio-political factors in the emergence of 'public' and 'private' domains in early Mesopotamia", in M. Hudson e B. A. Levine, op. cit., p. 129-147; E. Bouzon, "O Templo, o Palácio e o Pequeno Produtor na Baixa Mesopotâmia Pré-Sargônica", Ensaios Babilônicos. Porto Alegre, Edipurcs, 1998, p. 13-37; P. Steinkeller, "Land-tenure conditions in third-millennium Babylonia: the problem of regional variation", M. Hudson e B. A. Levine (eds.), Urbanisation and land ownership in the ancient Near East (Peabody Museum Bulletin, 7), Cambridge, MA, Peabody Museum of Archaeology and Ethnology, 1999, p. 289-329; e G. Pettinato, "La proprietà fondiaria nella Mesopotamia del 3. millenio dal periodo di Gemdet Nasr alla 3a. dinastia di Ur" in: H. Klengel e J. Renger (eds.), Landwirtschaft im alten Orient (41e Rencontre Assyriologique Internationale), Berlin, Dietrich Reimer Verlag, 1999, p. 99-113. Para o período da terceira dinastia de Ur, ver G. Pettinato, Untersuchungen zur neusumerischen Landwirtschaft. Vol. 1. Napoli, 1967, e R. de Maaijer, "Land tenure in Ur III Lagash", in B. Haring e De R. Maaijer (eds.), Landless and Hungry? Access to land in early and traditional societies, Leiden, CNWS/Netherlands School of Asian, African, and Amerindian Studies, 1998, p. 50-73. Para a época sargônica, ver B. Foster, Administration and use of institutional land in Sargonic Sumer (Copenhagen Studies in Assyriology, 9), Copenhagen, Akademisk Forlag, 1982, e S. J. Bridges, The Mesag archive: a study of Sargonic society and economy, Yale University. Unpublished Ph.D., 1981. Os dados para a região setentrional durante o terceiro milênio são raros; ver, entretanto, T. J. Wilkinson, "Settlement and land use in the zone of uncertainty in upper Mesopotâmia”, in R. M. Jas (ed.), Rainfall and agriculture in northern Mesopotamia (MOS Studies, 3), Leiden, Nederlands Historisch-Archaeologisch Instituut te Istanbul, 2000, p. 3-35; e G. Van Driel, "The Mesopotamian north: land use, an attempt" in: R. M. Jas (ed.), op. cit., p. 265-299. Para os problemas teóricos do estudo da economia suméria, cf. S. J. Garfinkle, Private enterprise in Babylonia at the end of the third millennium BC. Columbia University, Unpublished Ph.D., 2000, p. 1ss.
} 
- dos templos e dos palácios - que, desde então, teriam se tornado residuais. O controle familiar sobre segmentos do espaço urbano e rural é uma realidade inquestionável, assim como um fenômeno complexo e que precisa ser avaliado dentro de um contexto em que as organizações complexas, mesmo após a passagem do terceiro para o segundo milênio, continuaram a exercer um papel preponderante. Por outro lado, deve-se evitar assimilar este controle familiar do território às modernas noções de propriedade privada; o acesso à terra variou consideravelmente e traduziu-se em diversas formas: por vezes, derivava da participação na comunidade rural (campos coletivos possuídos e cultivados por famílias), por vezes, da aderência às estruturas palacianas (terrenos cedidos a servidores como forma de pagamento) e, em certos casos, sobretudo no âmbito da elite urbana, de uma transmissão hereditária do patrimônio familiar. É principalmente neste último universo que a alienação pôde firmar-se como um dos ingredientes da capacidade de controle sobre o bem imóvel. Em contrapartida, nos casos dos terrenos de origem comunitária ou palaciana, a alienação era vigorosamente combatida como um desvio e um sinal de deterioração da autoridade da comunidade ou do palácio sobre a terra. ${ }^{3}$

Foi, sobretudo, a partir da década de 80 do século XX que as transferências de terrenos se tornaram um objeto prioritário da reflexão dos historiadores da antiga Mesopotâmia, no bojo de uma considerável renovação da historiografia econômica que, para se limitar ao essencial, elegeu os estudos dos arquivos privados como um campo privilegiado da análise da vida material. No entanto, as operações envolvendo imóveis foram analisadas quase exclusivamente do ponto de vista dos grupos familiares que adquiriam os bens. ${ }^{4}$

\footnotetext{
${ }^{3}$ Sobre a apropriação comunal, ver M. Rede, A apropriação do universo material. O controle do espaço em Larsa durante o Período Babilônico Antigo. Universidade Federal Fluminense. Dissertação de Mestrado inédita, 1994, capítulo 4. Para a administração palaciana das terras em Larsa, ver M. de J. Ellis, Agriculture and the state in ancient Mesopotamia. An introduction to problems of land tenure (Occasional Publications of the Babylonian Fund,1), Philadelphia, 1976; M. Rede, op. cit., capítulos 1-2, e M. Rede, "Terra e poder na antiga Mesopotâmia uma antropologia histórica entre os "primitivos" e os "modernos", Phoînix, 2, 1996, p. 109134, além dos trabalhos de M. Y. Ishikida, The administration structure and economic function of public service (ilkum) of the Old Babylonian state in the Old Babylonian Period. University of California, Los Angeles. Unpublished Ph. D., 1994.; "The structure and function of dispute management in the public administration of Larsa under Hammurapi”, Orient, 23, 1998, p. 66-78, e "The ilkum institution in the provincial administration of Larsa during the reign of Hammurapi (1792-1750 B.C.)", Orient, 24, 1999, p. 61-88.

${ }^{4}$ Neste quadro, uma rara exceção é o trabalho de N. Kozyreva, "Sellers and buyers of urban real estate in South Mesopotamia at the beginning of the 2 nd millennium B. C.", in M. Hudson e B. A. Levine (eds.), Urbanization..., op. cit., p. 353-356.
} 
Esta perspectiva teve, evidentemente, grandes conseqüências para a caracterização do próprio fenômeno da circulação imobiliária e, em particular, para a construção de uma visão predominante - mas, a meu ver, equivocada - de um triunfo inexorável dos grupos privados nos reinos semitas ou amorritas que se seguiram à derrocada do período sumério dominado pela terceira dinastia de Ur (2112-2004), visto, por um contraste conveniente, como "estatizante" por excelência. Como não poderia deixar de ser, a figura do mercador (dam-gàr, em sumério; tamkârum, em acadiano) foi identificada como um dos motores deste desenvolvimento em direção a uma economia privada e, mais particularmente, como um dos principais agentes da circulação de imóveis. Em outro texto, critiquei severamente esta perspectiva, e não é questão, aqui, de revisar o problema inteiramente. ${ }^{5}$ Limitar-me-ei, apenas, a lembrar que, no que diz respeito aos compradores, nenhum grupo, nem mesmo o dos mercadores, atuou como verdadeiro negociante de terras, intermediando operações, fazendo circular os imóveis e acumulando, a cada etapa, um capital oriundo dos lucros daí provenientes. Longe desta visão quase caricatural, mas bastante difundida, a análise aprofundada e serial dos dados disponíveis mostra um comportamento aquisitivo orientado para o aumento do patrimônio familiar, preferencialmente incorporando terrenos vizinhos que, após adquiridos, jamais são revendidos, mas transmitidos em herança para a geração seguinte. Há, pois, acumulação fundiária, urbana e rural, mas não um empenho na circulação incessante de imóveis a fim de majorar o investimento inicial. Por outro lado, o horizonte das operações não é um mercado aberto, no qual compradores buscariam as melhores oportunidades de aquisição, mas o domínio mais restrito e controlado das relações de parentesco e de vizinhança, pelas quais, por meio de longas negociações (que seriam consideradas muito pouco racionais do ponto de vista de uma estrita racionalidade capitalista), os compradores realizam grande parte de suas aquisições.

Muitos problemas que dificultam análises mais equilibradas e adequadas da circulação imobiliária vêm do fato de que elas se baseiam nos arquivos reunidos pelos compradores. Esta é uma característica do processo de formação dos arquivos privados na antiga Mesopotâmia: os contratos que registram uma transferência são guardados pelo comprador, como garantia da legitimidade da operação contra futuras reivindicações; a estes documentos somam-se todos os anteriores que mostram a trajetória do bem até aquele momento e que são ${ }^{5}$ M. Rede, L'Appropriation de l'Espace Domestique: La Trajectoire de la Famille Sanum. Université de Paris I - Panthéon-Sorbonne. Tese de Doutorado inédita, 2004, p. 135 ss. 
igualmente transferidos pelo vendedor ao comprador junto com o próprio bem; o resultado é um arquivo familiar composto de vários "títulos de propriedade". ${ }^{6}$ Por outro lado, do ponto de vista interno, cada contrato era redigido ex latere emptoris, isto é, do ponto de vista do comprador (em oposição a uma formulação ex latere venditoris), o que contribuiu para condicionar a visão do historiador a partir da própria natureza da fonte. Estes fatores heurísticos explicam bastante as atuais tendências predominantes nos estudos da economia familiar, mas é preciso também acrescentar que uma orientação teórica privilegiou a ação econômica dos grupos mais bem posicionados da sociedade, em particular das elites urbanas, conferindo, em contrapartida, pouca atenção às famílias que se encontravam em posição de desvantagem. Como, no momento da transferência do imóvel, estes dois pólos correspondem, grosso modo, aos compradores e aos vendedores, a história da economia familiar limitou-se a ser uma história da trajetória dos primeiros. Paradoxalmente, embora a história das famílias e de suas atividades seja considerada como uma contrapartida da história centrada nos grupos dominantes dos templos e palácios, é preciso reconhecer que, no essencial, ela não rompeu com a perspectiva tradicional de uma história "a partir do topo".

É possível, entretanto, superar pelo menos algumas das limitações impostas pelo caráter das fontes e, utilizando os dados dos mesmos contratos imobiliários, redigidos sob os auspícios e para o interesse dos compradores, procurar estabelecer alguns padrões do comportamento de alienação. Por que os indivíduos e as famílias dispõem de seus imóveis? Como se apresentam os vendedores? Qual a importância das relações de parentesco na venda do patrimônio? É possível delimitar certas tendências de disposição em função de outras variantes, como, por exemplo, os preços?

As repostas a estas questões só podem ser parciais e indicativas. No entanto, parece-me que uma tentativa bem controlada, a partir de um estudo de caso e manipulando dados documentais tratados serialmente, pode contribuir para esclarecer alguns aspectos e apontar perspectivas.

O caso de Larsa pode ser considerado um campo de provas privilegiado. Foi ele que serviu de base a várias das primeiras formulações, nos inícios da

${ }^{6}$ Ver C. Saporetti, Assur 14446: La famiglia A. Acesa e declino di persone e famiglie all'inizio del medio-regno assirio, vol. 1. Malibu, Undena Publications, 1979, p. 8, e, sobretudo, D. Charpin, "Transmission des titres de propriété et constitution des archives privées en Babylonie ancienne", in K. R. Veenhof (ed.), Cuneiform archives and libraries (30e Rencontre Assyriologique Internationale). Leiden, Nederlands Historisch-Archaeologisch Instituut te Istanbul, 1986, p. $121-140$. 
década de 1950, acerca das transferências de imóveis e da economia "privada" do período Babilônico Antigo, com os trabalhos pioneiros de L. Matoush e W. F. Leemans. ${ }^{8}$ Mais recentemente, com o florescimento dos estudos de arquivos privados, a documentação de Larsa proporcionou um conjunto significativo de dados para os autores que centraram sua atenção na "política imobiliária dos mercadores", os quais, em grande medida, prolongaram a perspectiva "privatista" mencionada anteriormente. ${ }^{9}$ No atual estado das publicações, existem 143 contratos de alienação de imóveis provenientes de Larsa (atual sítio de Tell Senkereh), datados dos reinos dos dois últimos soberanos da fase independente do reino, Warad-Sîn (1835-1823) e seu irmão Rîm-Sîn (18221763), imediatamente anteriores à anexação de Larsa por Hammu-rabi, rei da Babilônia. Estes contratos formarão a base de dados para as considerações que se seguem. ${ }^{10}$ ${ }^{7}$ Para as transmissões por herança, ver L. Matoush, "Les contrats de partage de Larsa prove-
nant des archives d'Iddin-Amurrum", Archiv Orientální, 17, 1949, p. 142-175; para as vendas,
ver L. Matoush, "Les contrats de vente d'immeubles provenant de Larsa", Archiv Orientální,
18, 1950, p. 11-67.

${ }^{8}$ W. F. Leemans, The Old-Babylonian merchant. His business and his social position (Studia et Documenta ad Iura Orientis Antiqui Pertinentia, 3), Leiden, E. J. Brill, 1950.

${ }^{9}$ Ver, por exemplo, D. Charpin, "La politique immobilière des marchands de Larsa à la lumière des découvertes épigraphiques de 1987 et 1989", in J.-L. Huot (ed.), Larsa. Travaux de 1987 et 1989 (Bibliothèque Archéologique et Historique, 165), Beyrouth, Institut Français d'Archéologie du Proche-Orient, 2003, p. 311-322, assim como algumas teses relativamente recentes: S. R. Harris, Land conveyance in Old Babylonian Larsa, Michigan, University of Michigan. Unpublished Ph.D., 1983, e K. M. P. Pozzer, Les archives privées de marchands à Larsa pendant la deuxième moitié du règne de Rîm-Sîn, Université de Paris I - Panthéon-Sorbonne, Tese de Doutorado inédita, 1996.

${ }^{10}$ Um conjunto de 98 contratos de Larsa foi publicado, em transcrição do cuneiforme e tradução em português, pelo Prof. E. Bouzon, Contratos Pré-Hammurabianos do Reino de Larsa, Porto Alegre, Edipucrs, 2000, e me permitiram uma primeira abordagem do tema sob sua direção: M. Rede, A apropriação..., op. cit. Posteriormente, no quadro de um doutorado realizado na Universidade de Paris - Sorbonne, sob orientação do Prof. D. Charpin, pude alargar a base documental para os 143 contratos hoje disponíveis, formando uma base informatizada com todos os dados cadastrais disponíveis no corpus: nomes de vendedores, compradores, vizinhos e testemunhas; preços; dimensão, tipo e localização dos terrenos; datas etc. cf. M. Rede, L’Appropriation..., op.cit., vol. 2. Os tabletes de Larsa estão concentrados nos museus de Berlin, de Yale e do Louvre e suas cópias foram publicadas em suas respectivas séries de edições de documentos cuneiformes (VS, YOS e TCL). Estas três grandes coleções formavam a base da edição de E. Bouzon. A elas devem-se acrescentar as coleções de Liagre Böhl, em Leiden (publicadas em TLB), do Museu de Leningrado, hoje São Petesburgo (publicadas por A. P. Riftin, Starovavilonskie Juridiceskie i Administrationie Dokumentiv Sobranijach SSSR. Moskau/Leningrad, 1937), os tabletes da Universidade de Liège (editados por H. Limet, "Amurru-shemi, propriétaire foncier à Larsa", Akkadica, Supplementum, 6, 1989, p. 99-111), além de peças isoladas espalhadas por diversos museus. Um número considerável de contratos de Larsa encontra-se repertoriado nos catálogos da Universidade de Yale e aguarda publicação; cf. G. Beckman, Old Babylonian archival texts in the Nies Babylonian collection (Catalogue of the Babylonian Collections at Yale, 2), Bethesda, CDL Press, 1995, e Old Babylonian archival texts in the Yale Babylonian collection (Catalogue of the Babylonian Collections at Yale, 4), Bethesda, CDL Press, 2000. 
Quando analisamos as negociações de terrenos em Larsa durante o período considerado aqui (1835-1763 a.C.), notamos um número limitado de compradores: nos 143 registros contratuais, aparecem os nomes de apenas 55 compradores. A situação dos vendedores é inversa: no total, são conhecidos 169 nomes diferentes de pessoas que venderam seus terrenos. ${ }^{11}$ Assim, houve, em Larsa, uma média de 0,38 comprador por transação imobiliária, enquanto a proporção de vendedores eleva-se a $1,27 .^{12}$ Isto é o resultado estatístico de dois fatores diferentes e de grande importância para compreender a circulação imobiliária local. Em primeiro lugar, nota-se a ausência de grandes vendedores: do mesmo modo que a recorrência de um mesmo personagem atuando como comprador indica um processo de concentração fundiária na cidade, a ausência da mesma recorrência do lado dos vendedores mostra que o funcionamento do sistema não repousava sobre a presença de negociantes habituais de terrenos, o que é ainda mais verdadeiro quando se constata que os vendedores que aparecem em mais de um contrato não fazem parte do grupo de grandes compradores. Em Larsa, portanto, o vendedor típico alienou seus terrenos uma única vez e não era simultaneamente um comprador. Em segundo lugar, o número elevado de vendedores, em relação à quantidade de operações, é o resultado da presença de grupos de vendedores: em 44 contratos $(30,77 \%$ do total), a venda é feita por mais de um vendedor explicitamente nomeado no contrato, até um máximo de cinco pessoas (ver Gráfico 1). ${ }^{13}$ Em contraste, notar-se-á que a presença de grupos de compradores é bem menos importante: 10 atestações, ou seja, apenas $7 \%$ dos contratos.

${ }^{11}$ É impossível restituir o número exato de nomes, pois em oito casos eles não são legíveis nos tabletes (em três casos, estão completamente perdidos; em cinco, encontram-se bastante deteriorados). É igualmente impossível estabelecer, a partir dos nomes, o número exato de vendedores (bem como de compradores), por causa dos homônimos: há 17 nomes que se repetem de duas a quatro vezes e não se pode saber com certeza se se trata da mesma pessoa, salvo quando o personagem é bem conhecido por outras fontes (como é o caso de Iddin-Nanaya, da família Sanum); ver o Quadro 1. Por fim, em um único caso (YOS, 5, 122), o vendedor foi um templo.

12 Em ambos os casos, os cálculos excluem os contratos em que os nomes não são legíveis.

${ }^{13}$ É interessante notar que esta percentagem é compatível com os cálculos de I. M. Diakonoff, "Extended family households in Mesopotamia (III-II millennia B.C.)", in K. R. Veenhof (ed.), Houses and households in ancient Mesopotamia. (40e Rencontre Assyriologique International), Leiden, Nederlands Historisch-Archaeologisch Instituut te Istanbul, 1996, p. 57, segundo os quais 30\% dos vendedores do Período Babilônico Antigo seriam compostos por grupos. Não somos obrigados, no entanto, a ver sempre, por trás destes grupos, as famílias alargadas, caras ao autor. O próprio Diakonoff distinguiu a situação de Ur (onde predominaria o modelo alargado da organização familiar) e a de Larsa (na qual "in the sales and leases, extended family communes are hardly attested", cf. p. 58). 


\section{Gráfico 1: Vendedores individuais e grupos de vendedores}

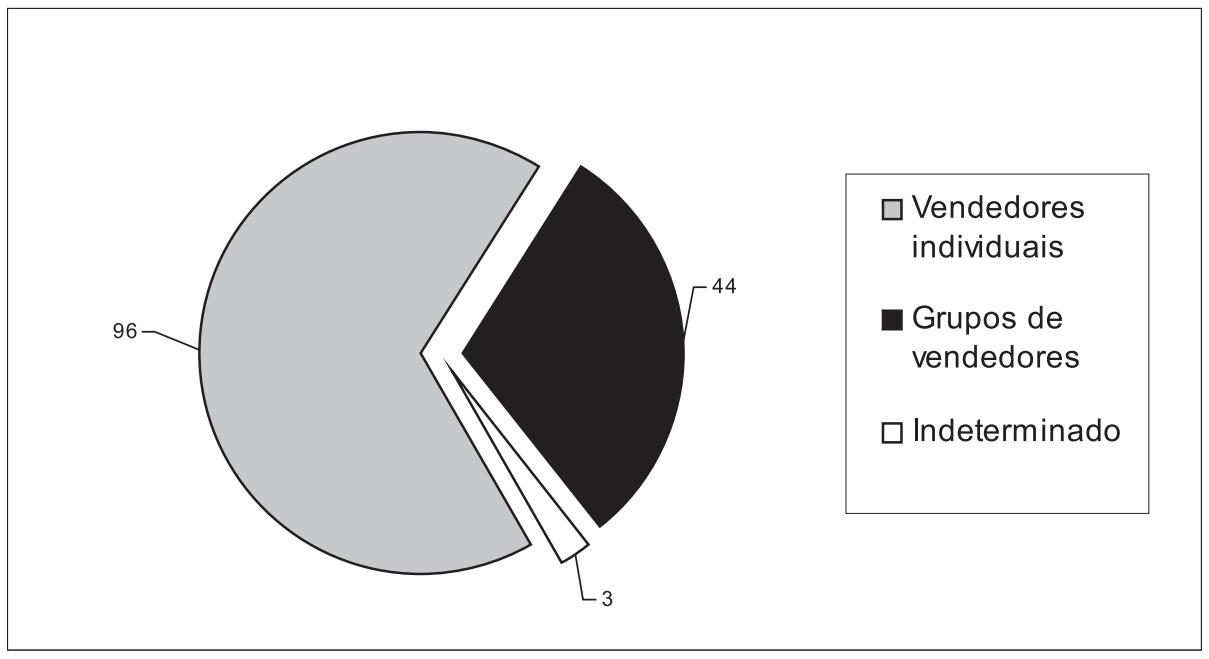

A observação destes grupos merece ser aprofundada. Uma característica importante encontra-se no fato de que a maior parte é formada por pessoas ligadas por laços de parentesco: em 31 dos 44 casos de vendedores coletivos (ou seja, 70,45\%), as relações de parentesco entre os vendedores podem ser restituídas com segurança. A percentagem deve, no entanto, ser ainda maior: entre os demais grupos de vendedores, certamente há famílias, embora o parentesco não esteja explícito no contrato. ${ }^{14} \mathrm{O}$ Quadro 1 resume todos os casos conhecidos:

Quadro 1: Grupo de vendedores Laços de parentesco e composição sexual

\begin{tabular}{|c|c|c|c|c|}
\hline $\mathbf{N}^{\circ}$ & Documento & $\begin{array}{l}\text { Número de } \\
\text { vendedores }\end{array}$ & $\begin{array}{l}\text { Laço de parentesco } \\
\text { entre os vendedores* }\end{array}$ & $\begin{array}{c}\text { Composição } \\
\text { sexual** }\end{array}$ \\
\hline 1 & $\mathrm{HE}, 201$ & 2 & Irmãos & $\mathrm{QD}$ \\
\hline 2 & Limet, 7 & 2 & Pai e filho & $\mathrm{QW}$ \\
\hline 3 & PSBA,34: 9 & 3 & Pai e dois filhos & WND \\
\hline
\end{tabular}

\footnotetext{
${ }^{14}$ Em certos casos (VS, 13, 94 e YOS, 8, 143), os dois vendedores são citados com suas respectivas filiações paternais: se isto garante que não se trata de irmãos agnáticos, não se pode excluir que se trate de parentes, por exemplo, primos. Por outro lado, a posse em comum do bem alienado pode também resultar de uma sociedade entre pessoas não aparentadas.
} 


\begin{tabular}{|c|c|c|c|c|}
\hline $\mathbf{N}^{\circ}$ & Documento & $\begin{array}{l}\text { Número de } \\
\text { vendedores }\end{array}$ & $\begin{array}{c}\text { Laço de parentesco } \\
\text { entre os vendedores* }\end{array}$ & $\begin{array}{c}\text { Composição } \\
\text { sexual** }\end{array}$ \\
\hline 4 & Riftin, 15 & 2 & Mãe e filho & 叫 \\
\hline 5 & Riftin, 19 & 2 & - & $\Delta$ \\
\hline 6 & Riftin,20 & 4 & $\begin{array}{l}\text { Pai, filho e dois outros } \\
\text { (cf. TCL, 10,14:19) }\end{array}$ & WNAD \\
\hline 7 & SAOC, 44,18 & indeterminado & Uma mulher "e sua familia" & $\nabla+X$ \\
\hline 8 & TCL, 10,26 & 2 & Mãe e filho & $\Delta \nabla$ \\
\hline 9 & TCL, 10,27 & 2 & - & 曲 \\
\hline 10 & TCL, 10,35 & 4 & - & 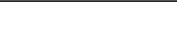 \\
\hline 11 & TCL, 10,50 & 3 & \begin{tabular}{|l|}
$\begin{array}{l}\text { Pai e dois filhos } \\
\text { (cf. TCL, 10,67: 9) }\end{array}$ \\
\end{tabular} & $\Delta \times \mathbb{D}$ \\
\hline 12 & TCL, 10,128 & 2 & - & 四 \\
\hline 13 & TLB, 1,2 & 3 & Mãe e dois filhos & 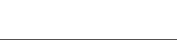 \\
\hline 14 & TLB, 1,3 & 2 & Irmãos & $\bar{\Delta}$ \\
\hline 15 & TLB, 1,8 & 2 & Irmãos & 雨 \\
\hline 16 & TLB, 1,16 & 2 & (contexto fragmentado) & 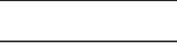 \\
\hline 17 & $\mathrm{VS}, 13,56$ & 3 & Pai, mãe e filho & 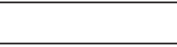 \\
\hline 18 & $\mathrm{VS}, 13,74$ & 2 & Irmãos & $\Delta$ \\
\hline 19 & $\mathrm{VS}, 13,75$ & 2 & Mãe e filho & $\nabla \nabla$ \\
\hline 20 & $\mathrm{VS}, 13,80$ & 2 & Casal & 为 \\
\hline 21 & $\mathrm{VS}, 13,88$ & 2 & Irmãos & $\overline{\nabla D}$ \\
\hline 22 & $\mathrm{VS}, 13,93$ & 2 & - & 曲 \\
\hline 23 & $\mathrm{VS}, 13,94$ & 2 & $\begin{array}{l}\text { Dois homens com filiação paterna } \\
\text { diferente }\end{array}$ & 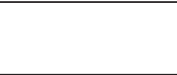 \\
\hline 24 & $\mathrm{VS}, 13,99$ & 2 & - & $\mathrm{QD}$ \\
\hline 25 & YOS, 5,112 & 3 & $\begin{array}{l}\begin{array}{l}\text { Pai e dois filhos ou } \\
\text { pai, filho e neto }\end{array} \\
\end{array}$ & $\overline{\Delta M D}$ \\
\hline 26 & YOS, 5,121 & 3 & Pai, mãe e filho & $\mathrm{W} \times \mathrm{X}$ \\
\hline 27 & YOS, 5,123 & 3 & Pai, mãe e filho & $\Delta \mathrm{WW}$ \\
\hline 28 & YOS, 5,125 & 2 & - & $\nabla \times$ \\
\hline 29 & YOS, 5,126 & 2 & Pai e filho & $\Delta \mathrm{W}$ \\
\hline 30 & YOS, 5,127 & 2 & - & $\Delta \nabla$ \\
\hline 31 & YOS, 5,143 & 5 & $\begin{array}{l}\text { Quatro homens (irmãos?) e a esposa de } \\
\text { um deles }\end{array}$ & VWNAD \\
\hline 32 & YOS, 8,6 & 2 & Irmãos & $\Delta \nabla$ \\
\hline 33 & YOS, 8,38 & 3 & Pai, mãe e filho & WWD \\
\hline 34 & YOS, 8,47 & 2 & - & $\Delta \otimes$ \\
\hline 35 & YOS, 8,79 & 3 & - & WNQ \\
\hline 36 & YOS, 8,80 & 2 & Pai e filho & 呕 \\
\hline 37 & YOS, 8,81 & 3 & Pai, mãe e filho & पQWV \\
\hline 38 & YOS, 8,124 & 3 & Pai, filho e filho da esposa $* * *$ & WND \\
\hline 39 & YOS, 8,132 & 2 & Irmãos (contexto fragmentado) & $\Delta \otimes$ \\
\hline 40 & YOS, 8,134 & 2 & Irmãos & $\Delta$ \\
\hline
\end{tabular}




\begin{tabular}{|c|c|c|c|c|}
\hline $\mathbf{N}^{\circ}$ & Documento & $\begin{array}{l}\text { Número de } \\
\text { vendedores }\end{array}$ & $\begin{array}{l}\text { Laço de parentesco } \\
\text { entre os vendedores* }\end{array}$ & $\begin{array}{c}\text { Composição } \\
\text { sexual** }\end{array}$ \\
\hline 41 & YOS $, 8,143$ & 2 & $\begin{array}{l}\text { Dois homens com filiação paterna } \\
\text { diferente }\end{array}$ & 叫 \\
\hline 42 & YOS, 8,156 & 2 & Irmãos & 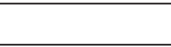 \\
\hline 43 & YOS, 8,176 & 2 & Casal & 叫 \\
\hline 44 & YOS, 14,129 & 2 & Casal & 叫 \\
\hline
\end{tabular}

* Na categoria "pai, mãe e filho", eu considero todas as ocorrências documentais da seqüência "X (homem), Y (mulher) dam-a-ni Z dumu-ni"; a rigor, $Z$ pode ser filho somente de $Y$, no caso de X ser o seu segundo marido, mas o próprio fato de o grupo vender coletivamente o imóvel sugere que se trate de uma família biológica.

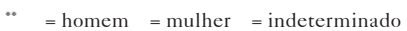

* Em YOS,8,124, a formulação da filiação de Apil-ilishu poderia sugerir enganosamente que ele fosse filho de Ahum; entretanto, YOS,8,125 permite restituir a árvore genealógica da família assim: Silli-Irra, sua esposa Ahatum e seus dois filhos, Apil-Ilishu e Awil-Adad. No mais, a partir de YOS,8,81, sabemos que Ahum é filho de Ahatum com outro marido, chamado Uqûa. Assim, Ahum e Apil-ilishu são, de fato, meio-irmãos uterinos (isto é, filhos de Ahatum, mas de pais diferentes). Em YOS,8,124, o grupo de vendedores é, portanto, composto pelo pai, Silli-Irra, e dois filhos, Ahum e Apil-ilishu, dos quais apenas o segundo é seu consangüíneo.

As relações de parentesco que ligam os membros de um grupo de vendedores eram, portanto, diversas. Sua tipologia pode ser mais bem visualizada no Quadro 2:

\section{Quadro 2: Laços de parentesco nos grupos de vendedores}

\begin{tabular}{|l|c|}
\hline \multicolumn{1}{|c|}{ Parentesco } & Ocorrências \\
\hline Irmãos & 9 \\
\hline Pais e filhos & 7 \\
\hline Mãe e filhos & 4 \\
\hline Casais & 3 \\
\hline Casais com filhos & 5 \\
\hline Outros/Indeterminados & 3 \\
\hline
\end{tabular}

A constatação mais importante é que os dados mostram claramente que a decisão de venda é tomada, sobretudo, por grupos de consangüíneos (20 casos), contra uma minoria de grupos por aliança de casamento (3 casos). A presença de grupos mistos, formados por aliança e filiação (6 casos), não altera o quadro: 


\section{Gráfico 2: Grupo de vendedores - Consangüinidade}

\section{e aliança de casamento}

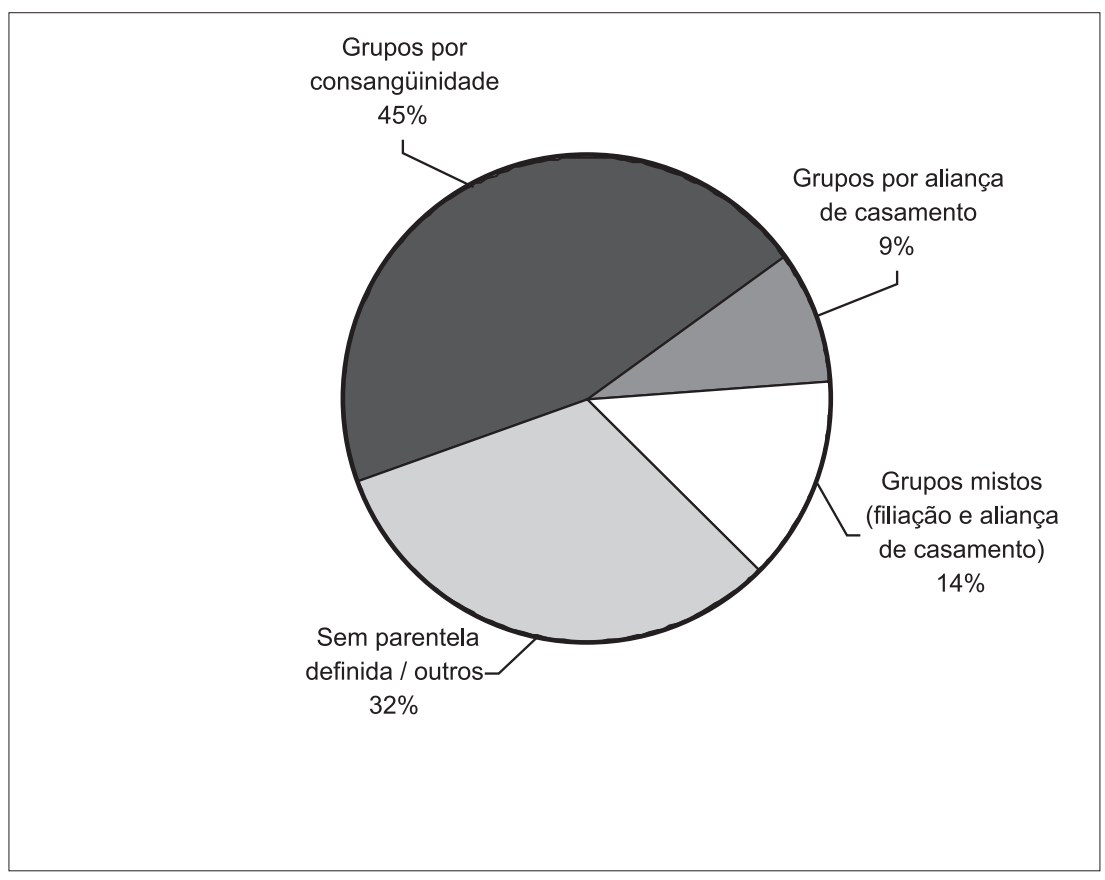

A preponderância dos grupos de consangüinidade no processo de disposição dos imóveis é, no mais, perfeitamente compatível com o sistema de controle dos bens fundiários em Larsa, definido no quadro das relações de filiação: a transmissão do patrimônio entre as gerações dava prioridade à filiação como instrumento de preservação da unidade territorial do grupo, em detrimento da migração dos imóveis em função da aliança de casamento. O resultado das estratégias de herança era, então, a formação de um grupo de consangüíneos que partilhavam o controle sobre o patrimônio imobiliário da família, concentrando-o nas mãos dos filhos e evitando que se dispersasse com o casamento das filhas. Estas, por sua vez, eram preferencialmente dotadas com bens móveis, prata, escravos, gado etc. A conseqüência é o que acabamos de constatar: nas situações de alienação do patrimônio imobiliário, os que detêm o poder de decisão são, sobretudo, os consangüíneos. No interior desta categoria, o primeiro lugar ocupado pelos grupos de irmãos deriva, 
sem dúvida, da negociação de imóveis recebidos em herança e cuja venda se apresentava como uma solução mais adequada e atraente do que uma divisão física do terreno ou da casa.

Existe um outro elemento importante que deve ser explicado: a presença de mulheres entre os vendedores. Uma vez mais, a diferença em relação à composição dos grupos de compradores é sugestiva. Entre estes últimos, as mulheres eram praticamente ausentes: nos dois únicos casos atestados, as mulheres compram imóveis em companhia de um homem: Hunabatum com seu marido Amurrum-shêmi ${ }^{15}$ e Shât-Sîn com seu filho Nabi-ilishu. ${ }^{16}$ Considerando que Hunabatum aparece como compradora em três ocasiões e que Shât-Sîn comprou uma única vez, a participação feminina reduz-se a somente 2,35\% das operações. Em contrapartida, as mulheres participam como vendedoras em 18,88\% das transações imobiliárias. ${ }^{17}$ Se considerarmos somente as vendas por grupos, elas estão presentes em 18 dos 44 casos (40,9\%). Como explicar este contraste?

Um primeiro aspecto está ligado ao fato de que a diferença de posição entre vendedores e compradores repercute na redação do contrato imobiliário. Um comprador, mesmo agindo em nome de seu grupo familiar, não sente necessidade de mandar incluir, no documento, os nomes de seus parentes: o bem adquirido pertencia à família e os mecanismos de devolução garantiriam a sua transmissão no interior do grupo (assim, no momento da partilha, os herdeiros seriam nomeados no contrato de herança). Ao contrário, a enumeração exaustiva de todos os nomes dos membros de um grupo de vendedores era desejável, a fim de evitar reclamações futuras por parte dos detentores de direito. Isto, sem dúvida, incitou a inscrever nos contratos os nomes das mulheres das famílias de vendedores. ${ }^{18}$ Esta atitude era, no entanto, o resultado de configurações familiares particulares: em geral, nas condições consideradas como normais - quer dizer, de controle masculino sobre o patrimônio imobiliário - a menção somente do homem titular de direito era suficiente para legitimar o ato de alienação. Nos demais casos, em que as mulheres eram citadas, é possível supor a existência de situações mais ou menos alternativas,

\footnotetext{
${ }^{15}$ Limet, 1,2 e 8.

${ }^{16}$ YOS, 5, 144.

${ }^{17}$ Além da presença das mulheres no interior de grupos de vendedores (mostrada no Quadro 1), é preciso acrescentar os nove casos em que uma mulher vende sozinha um imóvel.

${ }^{18}$ A importante presença dos filhos (17 ocorrências em 44 casos) pode ser explicada do mesmo modo.
} 
nas quais a regra do predomínio masculino cedia lugar a várias práticas que integravam a mulher no controle dos bens fundiários. Nós podemos tentar isolar algumas destas situações.

A primeira era a viuvez. ${ }^{19}$ Em Larsa, o nascimento de um filho contribuía para reforçar a posição da mulher em relação ao patrimônio do casal, pois sua descendência tornava-se herdeira legítima e prioritária dos bens, em detrimento da linhagem do marido. Se a mulher não era considerada como a titular do direito sobre o patrimônio fundiário, ela era contemplada pelo usufruto dos bens que, no futuro, deveriam ser repassados aos filhos. Assim, a presença de filhos no casamento poderia garantir às mulheres um papel no controle de bens imóveis difícil de imaginar de outro modo. Na prática, entretanto, vários motivos podiam incitar, ou mesmo obrigar, a uma alienação da casa ou dos terrenos antes que os filhos tomassem plena posse da herança. Neste caso, mãe e filho(s) - pois as filhas jamais aparecem em tal situação - deviam entrar em acordo para fazer a venda. Foi, provavelmente, o caso dos quatro contratos em que mãe e filho são registrados como vendedores. Um outro exemplo mostra que a ausência do marido permite à mulher aceder a uma posição excepcional de controle e, por conseqüência, de disposição dos bens fundiários, ao mesmo tempo em que mostra os limites do seu poder: um dos terrenos adquiridos por Iddin-Amurrum, grande comprador de terras de Larsa, foi vendido por uma mulher chamada Nihdushim, mas o contrato precisa que se tratava de um bem que pertencia a seu marido Sîn-gaia, provavelmente morto. ${ }^{20}$ Ora, neste caso, nenhum filho do casal está presente e parece que é justamente por isso que um homem da parentela (certamente, o irmão da esposa) intervém como intermediário da operação. ${ }^{21}$

\footnotetext{
${ }^{19}$ Os dados não são suficientes para que se possa falar com segurança de uma curva ascendente da viuvez em conseqüência das guerras levadas a cabo pelos reis de Larsa, em particular RîmSîn. A hipótese é, em todo caso, bastante plausível. Eu me limito, aqui, a algumas situações isoladas.

${ }^{20}$ TCL, 10, 89.

${ }^{21}$ A linha 15 do contrato registra: inim-ta a-wi-ia-tum [shesh]-a-ni = "pelo intermédio de Awiatum, seu irmão". A expressão suméria inim-ta equivale ao acadiano ana qab̂̂, e a tradução seguida, aqui, é a proposta por M. Tanret e C. Janssen, "'ana qabề - qui remplace qui?", Nouvelles Assyriologiques Brèves et Utilitaires, 3, 1992, p. 66. Não se pode excluir que o contrato engajava o intermediário como garantia da regularidade do contrato e da execução das obrigações implicadas, como sugeriu E. Szlechter, "Le régime des sûretés personnelles à l'époque de la première dynastie de Babylone", Revue Internationale des Droits de l'Antiquité, 10, 1963, p. 77-90.
} 
A viuvez pode, igualmente, estar na origem de situações em que as mulheres vendiam os bens provenientes da herança de seus maridos. ${ }^{22}$ É possível que a ausência de potenciais herdeiros na linhagem do marido (pais, irmãos, sobrinhos etc.) acabasse por beneficiar a mulher, mesmo se o casal não tivesse tido filhos. Pode-se dizer, portanto, que a mulher se beneficiava das lacunas na linha de devolução e era uma herdeira secundária dos bens fundiários, fossem eles da sua própria família, fossem da família de seu marido.

Por sua vez, as vendas realizadas pelos grupos com ou sem filhos (cinco e três casos, respectivamente) podem corresponder a situações diferentes, mas há grande probabilidade de que estejam ligadas à posição da mulher no processo de devolução de seu próprio grupo de parentela. Em uma primeira hipótese, os imóveis do casal podem ter sido comprados, ao menos em parte, com o dote (não-imobiliário) da esposa; em uma segunda possibilidade, o patrimônio do casal pode ter sido formado por terrenos recebidos pela mulher, cuja família carecia de herdeiros do sexo masculino. Em ambos os casos, a posição excepcional da mulher no controle dos imóveis justificaria sua menção explícita no contrato como vendedora ao lado do marido e dos filhos. Em particular, no caso de ausência de filhos, o procedimento serviria para prevenir reivindicações dos membros da linhagem da mulher, sobretudo os colaterais (irmãos) e seus descendentes (sobrinhos).

Uma última possibilidade, que também poderia explicar parcialmente o desequilíbrio da composição sexual entre os grupos de compradores e vendedores, é a de certos terrenos que podem ter sido adquiridos por homens e que, em caso de morte ou de ausência destes, foram vendidos pelas mulheres. Esta hipótese não é, entretanto, atestada nos contratos de Larsa: em certos casos, uma mulher aparece como a única vendedora registrada, mas nem sempre se pode adivinhar o contexto que explica a situação ou a origem do imóvel alienado.

Outra questão importante no que diz respeito às vendas realizadas por grupos é a natureza do terreno negociado. Os dados disponíveis mostram que os fatores que conduzem à cessão imobiliária pelos grupos atingem de modo eqüitativo o patrimônio urbano e rural: em 44 casos, 21 correspondem à alienação de terrenos urbanos (casas, pequenos terrenos vazios, imóveis em ruínas) e 21 referem-se à venda de terrenos rurais (pomares, grandes terrenos incultos, campos):

\footnotetext{
${ }^{22}$ No único caso atestado em Larsa (YOS, 5, 37), Shât-Eshtar vendeu um pequeno terreno inculto que provinha da parte de herança $(h a-l a)$ de seu marido, Umayatum.
} 


\section{Gráfico 3: Tipologia dos terrenos alienados pelos grupos de vendedores}

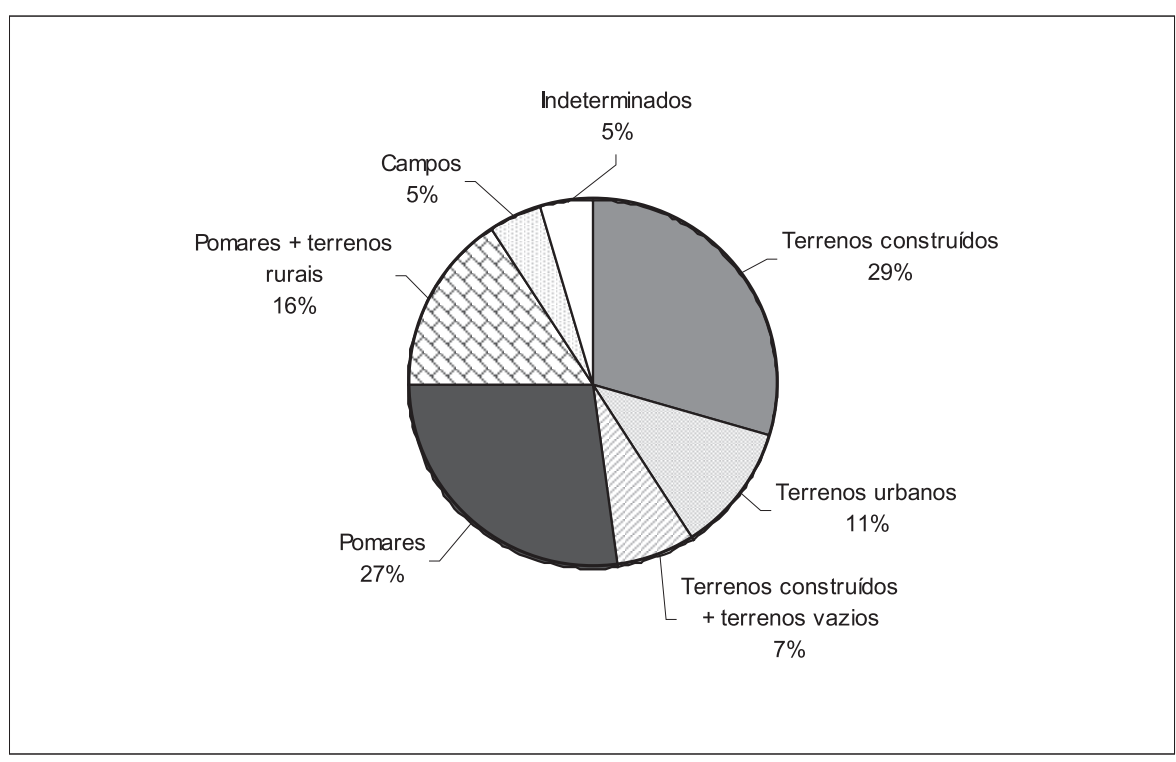

Para os grupos de vendedores, e particularmente para as famílias, a cessão imobiliária representou, portanto, a perda ou diminuição do espaço residencial, mas igualmente do espaço produtivo. ${ }^{23}$ Parece, por outro lado, que a presença das mulheres no interior de grupos de vendedores modificava consideravelmente o quadro: a proporção de terrenos urbanos vendidos pelos grupos sexualmente mistos era mais importante do que a de terrenos rurais (ver Quadro 3). Isto poderia ser interpretado como uma tendência mais pronunciada das mulheres em alienar os bens urbanos. No entanto, a meu ver, outra explicação é possível: tal situação reflete, mais provavelmente, o fato de que, nos grupos da elite urbana de Larsa representados pelas fontes, a presença do controle feminino era maior no espaço doméstico citadino e mais voltado para a família, enquanto o domínio rural e exterior da produção permanecia

\footnotetext{
${ }^{23}$ Poder-se-ia pensar que os grupos alienam o patrimônio imobiliário em condições mais coercitivas do que os vendedores individuais, pois os primeiros obtêm, em média, um valor menor pelos terrenos urbanos (22,77 siclos de prata/sar de terreno) do que os últimos $(26,17$ siclos/sar). É preciso, no entanto, considerar que os dados não são decisivos, sobretudo porque, para os terrenos rurais, as diferenças se invertem ( 0,09 e 0,08 siclos/sar, respectivamente). (Obs.: Para todos os cálculos e gráficos, as seguintes equivalências devem ser consideradas: 1 siclo $=8$ gramas; $1 \mathrm{sar}=36 \mathrm{~m}^{2}$.]
} 
sob controle predominantemente masculino. Por decorrência, é natural que as mulheres fossem mais presentes nas negociações de terrenos urbanos.

\section{Quadro 3: Tipologia dos terrenos alienados pelos grupos sexualmente mistos}

\begin{tabular}{|l|c|}
\hline \multicolumn{1}{|c|}{ Tipo de terreno } & Ocorrências \\
\hline Terrenos urbanos & 11 \\
\hline Terrenos rurais & 6 \\
\hline Indeterminado & 1 \\
\hline Total & 18 \\
\hline
\end{tabular}

A presença, nos contratos, de vários vendedores não deve ser absolutamente considerada uma formalidade. Em primeiro lugar, ela manifesta um acordo coletivo para a alienação do bem e testemunha uma forma de solidariedade na tomada de decisão sobre o destino do patrimônio familiar. Em segundo lugar, ela visa extrair o bem fundiário da rede de relações na qual ele está incrustado: o acordo de irmãos, esposas ou filhos funcionava como um mecanismo de legitimação da transferência que deveria reduzir ou eliminar, ao menos potencialmente, futuras reivindicações fundadas sobre direitos familiares, embora saibamos que tais precauções não evitavam totalmente as contestações. ${ }^{24}$

Para ter uma visão mais ampla do papel dos vendedores, pode-se tentar, igualmente, identificar suas práticas de disposição mais constantes. Seria possível, na miríade de formas singulares de alienação de terrenos, delimitar algumas tendências que permitam estabelecer comportamentos correspondentes, em maior ou menor grau, a padrões de alienação?

Logo de início, notaremos um antagonismo no processo de compra e venda de terrenos em Larsa: enquanto uma das estratégias dos compradores

\footnotetext{
${ }^{24}$ Em um contrato em que o vendedor é uma família (YOS, 5, 112), o pagamento, além da prata normalmente utilizada, inclui também uma quantidade de grãos. Poder-se-ia ver, aqui, um resquício dos pagamentos paralelos in natura feitos aos detentores de direitos, tal como observamos nas transferências imobiliárias arcaicas do III ${ }^{\circ}$ milênio? Cf. I. J. Gelb, P. Steinkeller e R. M. Whiting, op. cit., p. 219ss. e 281ss. Em todo caso, a prática é rara em Larsa e no único outro caso conhecido de pagamento composto por outros bens além da prata (YOS, 8, 69), um único indivíduo figura como vendedor. É de se notar, ainda, que estes dois contratos pertencem aos arquivos de um mesmo grande comprador de terrenos de Larsa, Balmunamhe: seria tal forma de pagamento simplesmente uma idiossincrasia sua?
} 
é a de avançar sobre os territórios de seus vizinhos, visando acumular cada vez mais lotes contíguos, o comportamento dos vendedores é marcado por uma forte resistência a dispor totalmente de seu patrimônio fundiário. As negociações podem, assim, durar décadas e atravessar gerações. Um vendedor como Ribam-ilî, filho de Hunubum, alienou seus terrenos paulatinamente, em pequenas parcelas e com uma grande distância temporal entre cada operação: a primeira vez, no ano 2 do reinado de Sîn-iqîsham, e a segunda, no ano 10 de Warad-Sîn, sempre para o mesmo comprador, Eshtar-Ilî, da família Sanum. ${ }^{25}$ Entretempo, no ano 6 de Warad-Sîn, ele vendeu uma parcela de seus domínios a Ur-Kêsh, ${ }^{26}$ mas, três anos mais tarde, também este terreno terminou sob controle da família Sanum. ${ }^{27} \mathrm{O}$ mesmo comportamento foi adotado por outro vendedor, Sîn-ishmeanni, filho de Sîn-abî, quando o mesmo Eshtar-ilî tentou ampliar ainda mais o domínio familiar: entre suas duas vendas, passaram-se cinco anos. ${ }^{28}$ Finalmente, um terceiro vendedor, Sîn-bêl-ilî, cedeu um terreno na mesma região para Eshtar-ilî, mas guardou uma parcela deste pelo menos por três anos após a primeira venda. ${ }^{29}$

Iddin-Nanaya, filho de Sîn-shêmi e único membro da família Sanum a vender habitualmente terrenos, procedeu da mesma maneira quando, a partir do ano 8 de Rîm-Sîn, começou a alienar o seu patrimônio imobiliário, certamente recebido como herança: os dois terrenos urbanos que ele vendeu a seu primo Iddin-Amurrum foram transferidos com mais de um ano de intervalo. ${ }^{30}$

Esta resistência a vender os terrenos pode ter razões políticas e simbólicas que, infelizmente, não chegamos a entender completamente. A associação feita por Nely Kozyreva entre a posse de terrenos na cidade, o fato de pertencer à comunidade e o gozo de direitos dela decorrente sugerem que conservar a propriedade urbana era uma condição indispensável para garantir

25 TCL, 10, 129 e TCL, 10, 8, respectivamente.

26 TCL, 10, 15.

${ }^{27}$ TCL, 10,6 .

${ }^{28}$ TCL, 10, 7 (do mês 12 do ano 10 de Warad-Sîn) e TCL, 10, 22 (do mês 9 do ano 2 de RîmSîn).

${ }^{29}$ TCL, 10, 11 (do ano 12 de Warad-Sîn); nós sabemos que Sîn-bêl-ilî conservou uma parte de seu patrimônio a partir do documento TCL, 10, 22 (do ano 2 de Rîm-Sîn). Estes terrenos devem ser, ao que parece, relacionados com a compra realizada por Sîn-bêl-ilî pouco tempo antes (TCL, 10, 10, do ano 10 de Warad-Sîn).

${ }^{30}$ TCL, 10, 29 (do mês 9 do ano 8 de Rîm-Sîn) e TCL, 10, 36 (do mês 2 do ano 10 de Rîm-Sîn). No segundo contrato, o terreno é, justamente, qualificado de "parte restante" (ib-tag g $_{4}$. 
o laço "cívico". ${ }^{31}$ Por outro lado, pode ter havido também a interferência de fatores religiosos que contribuíam para atrelar os habitantes a suas casas: a presença das tumbas dos ancestrais no subsolo e de capelas de culto familiar, em particular, pode ter sido considerada como um fator inibidor da alienação do imóvel, mesmo que isto nem sempre tenha impedido as vendas. ${ }^{32}$

A venda parcial do imóvel também era praticada na zona rural. Para se dar um exemplo envolvendo o já citado Iddin-Nanaya, a venda de seus pomares às margens do canal Ishmellum foi feita em duas vezes: uma primeira parcela foi vendida a um certo Ubar-Shamash ${ }^{33}$ e a outra, a seu primo IddinAmurrum. ${ }^{34}$ A distância entre as duas operações foi de apenas um mês e é possível que, neste caso, a divisão do terreno em dois lotes seja o resultado de uma busca de condições mais vantajosas de venda, finalmente encontradas junto a vendedores diferentes.

\footnotetext{
${ }^{31}$ N. Kozyreva, op. cit.; ver os comentários de J. Renger no mesmo volume (p. 357). Ver também J. Renger, "Das Privateigentum an der Feldflur in der altbabylonischen Zeit" in: B. Bremtjes (ed.), Das Grundeingentum in Mesopotamien (Jahrbuch für Wirtschaftsgeschichte). Berlin, Akademie Verlag, 1988, p. 58. A mesma idéia havia sido desenvolvida por A. L. Oppenheim para explicar o fato de que as sacerdotisas-nadîtum freqüentemente conservavam uma pequena parcela (ezibtum) dos terrenos urbanos que alienavam. É preciso notar que, se a conservação de uma parcela de terreno podia garantir a preservação de direitos, ela poderia implicar, igualmente, a continuidade de certas obrigações para com o palácio (ver: A. Goddeeris, Economy and society in northern Babylonia in the early old Babylonian period - ca. 2000 - 1800 BC. (Orientalia Lovaniensia Analecta, 109), Leuven, Peeters, 2002, p. 356.

${ }^{32}$ I. M. Diakonoff, "Extended families in Old Babylonian Ur", Zeitschrift für Assyriologie, 75, 1985, p. 47-65, pensou, com efeito, que a presença de tumbas provavelmente explicaria o fato de que as casas jamais foram vendidas inteiras em Larsa: daí o fato de que, nos contratos, aparecem apenas cômodos de dimensões reduzidas, muito menores do que as casas exumadas pelos arqueólogos. M. Van De Mieroop "Thoughts on urban real estate in ancient Mesopotamia”, in M. Hudson e B. A. Levine (eds.), Urbanization..., op. cit., p. 261, por sua vez, minimizou os efeitos restritivos deste fator, citando casos em que a construção de novas residências implicou a remoção das antigas tumbas (como seria o caso, ao que parece, da casa de Ur-Utu em Sippar-Amnânum) ou, ainda, transferências de casas juntamente com as caves funerárias. Para Mieroop, o respeito aos mortos teria sido um fenômeno menos durável do que se supõe normalmente. Opinião diferente foi manifestada por K. Van Der Toorn, "Domestic religion in ancient Mesopotâmia", in K. R. Veenhof (ed.), Houses..., op. cit., p. 69-77. Em Emar, uma cláusula especial nos contratos de venda imobiliária trata da transferência das tumbas domésticas, e um ritual parece ter sido realizado nesta ocasião; ver J.-M. Durand, "Tombes familiales et culte des ancêtres à Emar", Nouvelles Assyriologiques Brèves et Utilitaires, 4, 1989, p. 85-88. Em último lugar, ver M. Rede, "Práticas funerárias, culto aos ancestrais e transmissão do patrimônio familiar na antiga Mesopotâmia", Revista do Museu de Arqueologia e Etnologia - USP, 14, 2004 (117-138).

33 TCL, 10, 32 (do mês 3 do ano 9 de Rîm-Sîn).

34 TCL, 10, 33 (do mês 4 do ano 9 de Rîm-Sîn).
} 
A fragmentação dos lotes para venda era um fenômeno bastante comum. No entanto, em virtude dos limites dos dados cadastrais disponíveis, nem sempre é possível identificar as situações em que uma venda corresponde apenas a uma parcela do terreno original. Nos casos mais explícitos, os contratos registram que o vendedor continuava sendo, após a venda, um dos vizinhos do terreno; isto ocorre em 10 casos (ou seja, 7,87\% dos contratos em que a vizinhança é explicitada). ${ }^{35}$ Aqui está a lista de ocorrências:

\section{Quadro 4: Terrenos fracionados para a venda}

\begin{tabular}{|c|c|c|c|}
\hline $\mathbf{N}^{\mathbf{0}}$ & Documento & Data & Tipo de terreno \\
\hline 1 & Limet,6 & _/VI/RS 48 & Rural \\
\hline 2 & RA,12 $: 201$ & 15/V/RS 36 & Rural \\
\hline 3 & TCL,10,6 & /XI/WS 9 & Urbano \\
\hline 4 & TCL,10,89 & 22/XI/RS 36 & Rural \\
\hline 5 & VS,13,79 & /XI/RS 38 & Rural \\
\hline 6 & VS,13,87 & 15/IX/RS 49 & Rural \\
\hline 7 & VS,13,88 & 26/III/RS 49 & Rural \\
\hline 8 & YOS, 8,68 & 18/III/RS 14 & Urbano \\
\hline 9 & YOS,8,124 & 18/IX/RS 38 & Urbano \\
\hline 10 & YOS, 8,128 & /_/RS 31 & Urbano \\
\hline
\end{tabular}

Em 60\% dos casos apresentados no Quadro 4, os terrenos fracionados para a venda eram rurais; isto pode indicar que a resistência a alienar totalmente o patrimônio seria mais forte quando se tratava dos meios de produção do que do espaço habitacional. Notar-se-á, igualmente, que o fenômeno da fragmentação dos terrenos rurais se concentra entre os anos 30 e 40 do reinado de Rîm-Sîn, justamente quando a venda deste tipo de imóvel aumenta em relação à de imóveis urbanos: parece, então, que houve, neste período, uma intensificação das condições que constrangeram certas famílias a alienarem seus bens fundiários, acompanhada, em contrapartida, por uma reação à perda completa da capacidade produtiva do grupo: a fragmentação para a

\footnotetext{
${ }_{35}$ Alguns outros casos podem ser considerados: 1. em YOS, 5, 131, é o pai do vendedor que permanece como vizinho; 2. em YOS, 8, 110, é provável que o vendedor Sîn-damiq fosse também registrado como vizinho, mas uma lacuna no tablete impede de confirmá-lo (den-zu[xxx]); 3. em TCL, 10, 26, é o canal de irrigação que bordeja o pomar que tem o mesmo nome do vendedor, Shumshunu-watar; talvez seja um indício de que a família continue a possuir terrenos na região após a venda.
} 
venda pode ter sido, assim, um mecanismo de defesa que permitia ao grupo salvaguardar uma fração mínima para sua subsistência. A presença, entre estes terrenos fragmentados, de campos de cultivo de cereais (a-shà) - que são, no entanto, muito raros entre os imóveis vendidos - não seria, portanto, uma coincidência.

Outra série de dados parece confirmar esta tendência mais acentuada da fragmentação no meio rural: apesar de algumas oscilações, a superfície média de terrenos incultos e de pomares alienados diminuiu com o tempo (ver Gráfico 4). Ela era de 78,8 sar durante o reino de Warad-Sîn, mas aumentou consideravelmente durante a primeira década do reinado de Rîm-Sîn (265,3 sar); no entanto, depois, ela caiu a menos da metade entre os anos 11 e 20 de Rîm-Sîn (100,2 sar); uma recuperação momentânea é verificada na década seguinte (167,5 sar); entretanto, as dimensões entram novamente em ritmo decrescente após a metade do reino (os dados, porém, são inexistentes entre os anos 50 e 60 de Rîm-Sîn). Por oposição, a superfície média dos lotes urbanos negociados (casas e terrenos vazios) mostra um comportamento inverso: ela é crescente desde o reinado de Warad-Sîn até a segunda década de Rîm-Sîn. Os valores relativos aos anos 31-40 de Rîm-Sîn corroboram a tendência de aumento da superfície, mas nenhuma informação é disponível para os anos 21-30, e uma única ocorrência é preservada para a última década deste soberano.

\section{Gráfico 4: Dimensões dos terrenos vendidos - Superfície média}

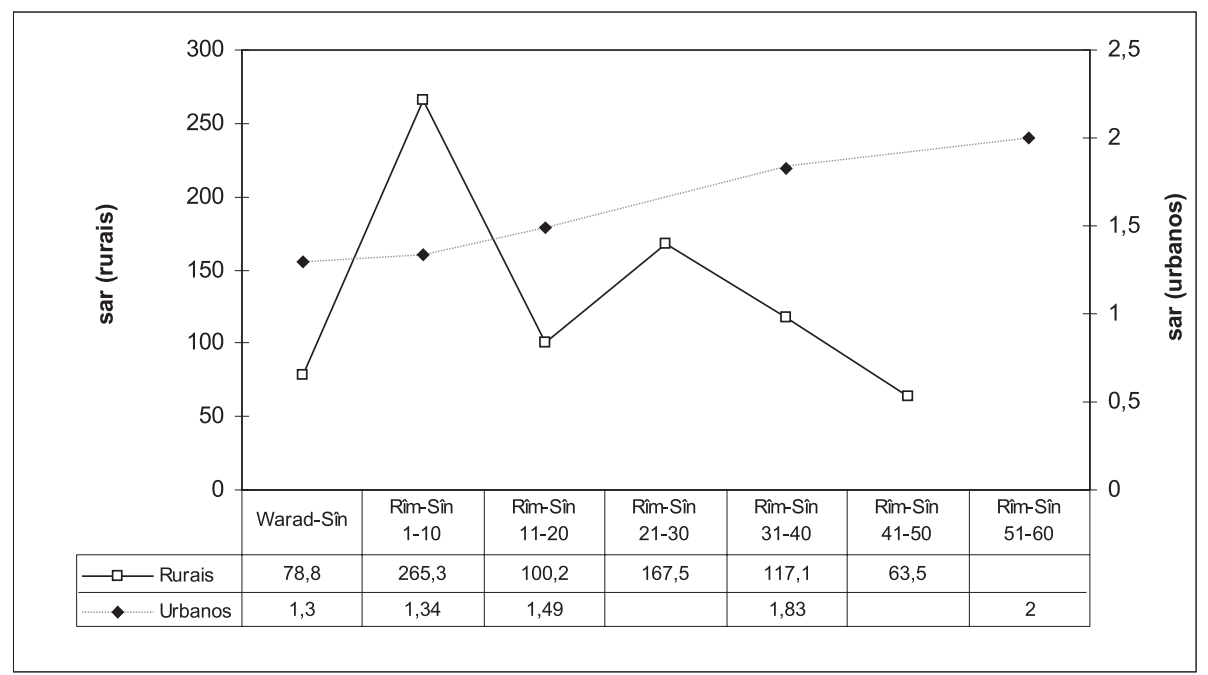


Outro modo de identificar as alienações graduais do patrimônio é verificar a recorrência de um mesmo vendedor em duas ou mais operações ao longo do tempo. O procedimento é metodologicamente dificultado pela presença de homônimos: nem sempre é possível saber, com certeza, se, por trás de um mesmo nome, temos o mesmo personagem. ${ }^{36}$ Dentre os vendedores que aparecem nos 143 contratos de Larsa, há 18 nomes que se repetem mais de uma vez. Em 10 destes casos, os dados não permitem distinguir entre os homônimos ou afirmar que se trata de um mesmo vendedor que alienou seu patrimônio imobiliário em parcelas. Ao menos em um caso, a homonímia é certa. Assim, para a atestação de um mesmo vendedor atuando mais de uma vez, restam 6 casos seguros e outro bastante provável. Este total de 7 casos corresponde a apenas 3,55\% dos vendedores conhecidos: uma taxa manifestamente baixa, que dificilmente permitiria sustentar a idéia da existência, em Larsa, de uma camada de agentes imobiliários, que teriam feito do comércio de terrenos uma atividade constante e sistemática de sua vida econômica. Por outro lado, se compararmos as situações em que um mesmo vendedor aparece repetidamente com aquelas em que os terrenos são fracionados para a venda (Quadro 4), notaremos algumas coincidências esperadas: dos 10 terrenos, quatro foram vendidos de modo parcelado por vendedores que atuaram mais de uma vez. Isto sugere que a venda fragmentada está associada a uma reincidência de certos proprietários obrigados a alienar os bens fundiários e que a participação repetida no circuito imobiliário como vendedor não impediu uma resistência a dispor do imóvel.

Um último aspecto do comportamento dos vendedores está ligado à quantidade de terrenos alienados e sua relação com o montante de prata obtido pela transferência. É impossível saber, em cada ocorrência, se uma necessidade circunstancial de prata impeliu à venda do patrimônio imobiliário e, neste caso, se a quantidade de prata a ser obtida foi o critério determinante dos limites das superfícies que o vendedor estaria disposto a alienar. Nos casos de endividamento, por exemplo, pode-se pensar que o vendedor tenderia a reduzir a venda de imóveis ao mínimo necessário para pagar suas dívidas, evitando, assim, a perda completa de seu terreno. Witold Kula chamou a atenção para um fenômeno corrente nas sociedades pré-capitalistas: entre os camponeses, verifica-se um comportamento bastante diferente daquele que

${ }^{36}$ Uma análise prosopográfica minuciosa, caso a caso, é feita em M. Rede, L'Appropriation..., op. cit., p. 247 ss. e Quadro 21. Aqui, eu me limito a fornecer sinteticamente os resultados da análise. 
caracteriza os proprietários fundiários modernos; estes últimos são levados a dispor de uma quantidade mais importante de terrenos durante a alta de preços, pois a terra funciona como um investimento intermediário em um mercado em que o objetivo último é o aumento do capital. A preocupação primordial da população camponesa pré-capitalista era, ao contrário, conservar sua base produtiva: assim, em face de um aumento de preço das terras, ela tende a satisfazer sua necessidade momentânea de recursos metálicos com a alienação de uma proporção menor da propriedade. O resultado global é que o montante das superfícies alienadas é inversamente proporcional ao nível de preço que pode ser alcançado com a venda. ${ }^{37} \mathrm{Em}$ um comentário a esta passagem, Robert McC. Adams apontou, apropriadamente, a dificuldade para verificar tal hipótese na realidade mesopotâmica, dado o silêncio do mundo rural nas fontes escritas disponíveis. ${ }^{38}$ Podemos, entretanto, tentar avaliar a reação dos vendedores de Larsa diante das variações do valor em prata dos terrenos negociados.

O movimento geral confirma a hipótese de W. Kula e não há, neste aspecto, diferenças notáveis entre a alienação de terrenos urbanos e rurais. Evidentemente a superfície dos terrenos vendidos variou consideravelmente, mas é possível constatar que tal variação era bastante sensível à relação prata/ superfície: maior a quantidade de prata que se podia obter por sar vendido, menor era a dimensão dos terrenos negociados. Os vendedores limitaram a disposição em função de uma alta efetiva, como mostram os Gráficos 5 e 6, nos quais as tendências são dadas separadamente para os terrenos urbanos e rurais:

\footnotetext{
${ }^{37}$ W. Kula, Teoría económica del sistema feudal, Ciudad del México, Siglo XXI, 1974.

${ }^{38}$ R. McC. Adams "Mesopotamian social evolution: old outlooks, new goals", in T. Earle (ed.), On the evolution of complex societies (Essays in honour of Harry Hoijer), Malibu, Undena Publications, 1984, p. 96.
} 
Gráfico 5: Relação entre superfície vendida e valor pago - Terrenos urbanos

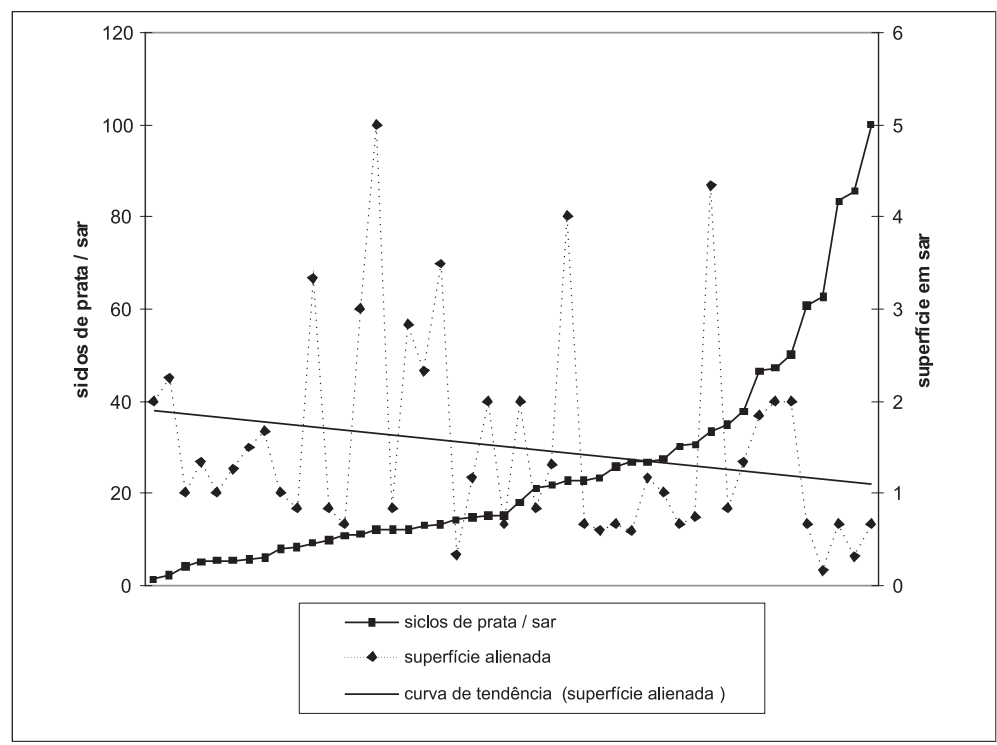

Gráfico 6: Relação entre superfície vendida e valor pago - Terrenos rurais

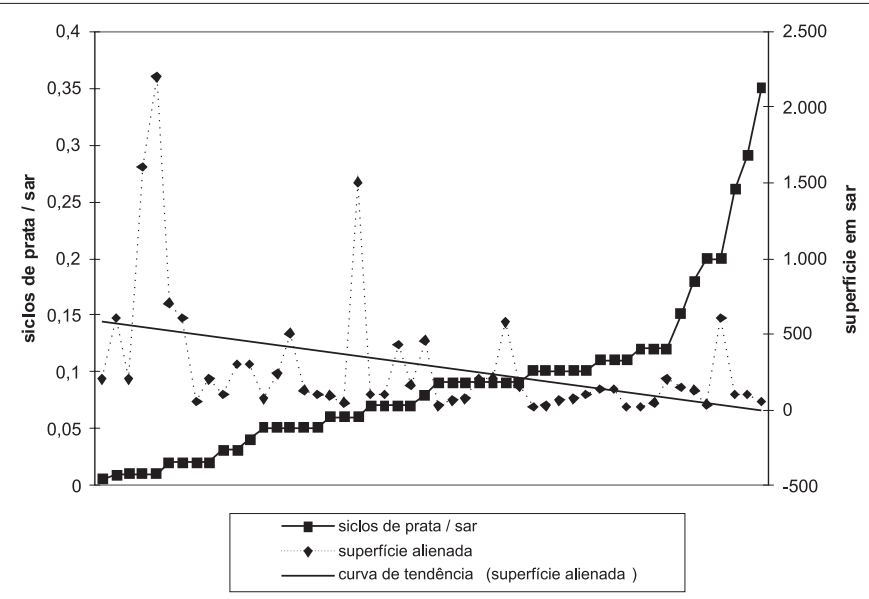


Se isolarmos os terrenos em função de seu tipo, notaremos uma única exceção importante. Para as vendas de pomares, o aumento do montante de prata não parece ter implicado uma mudança significativa do comportamento dos vendedores: estes não venderam mais para aproveitar a alta de preço, mas tampouco reduziram a superfície negociada. Como se vê no Gráfico 7, a curva de tendência da variação das superfícies alienadas mantém-se praticamente inalterada, apesar das variações de valor.

\section{Gráfico 7: Relação entre superfície vendida e valor pago - Pomares}

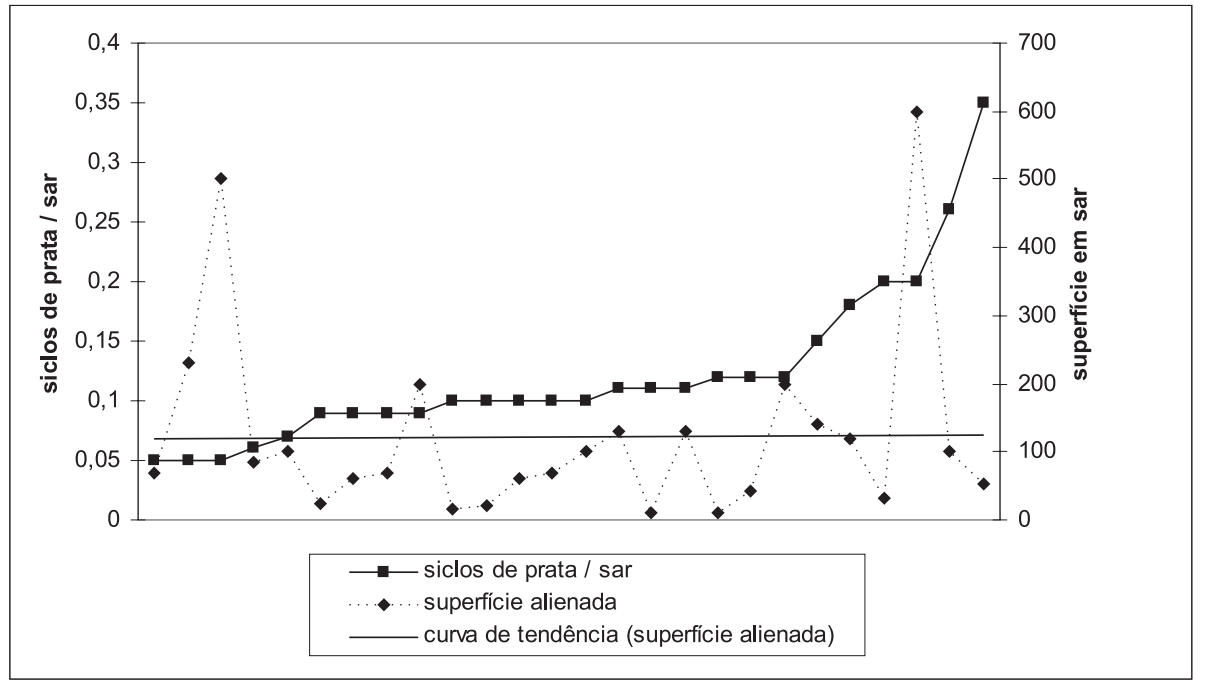

Como explicar esta diferença no comportamento de alienação? Parece que o fator decisivo está ligado ao processo de formação do preço. Os valores dos terrenos produtivos da zona rural são mais sensíveis a razões econômicas do que os terrenos urbanos e, portanto, seu perfil de variação flutua em função de fatores relativamente estáveis, determinados mais racionalmente. Neste quadro, a margem de manobra dos vendedores de pomares era menor, pois as variações de preço não lhes permitiam limitar consideravelmente as superfícies vendidas em função de eventuais altas. Em contrapartida, um processo de formação de preço menos fundado sobre a racionalidade econômica e no qual as variações eram não somente mais acentuadas como também mais aleatórias, como é o caso com os terrenos urbanos e casas, oferecia uma 
possibilidade de negociação que poderia beneficiar o vendedor. No caso de Larsa, compatível com a lógica pré-capitalista, o benefício não significou um lucro mais elevado, mas a possibilidade de vender uma parcela menor do imóvel. O caso dos pomares aparece, então, como uma exceção que confirma a regra geral do comportamento de alienação, que tendia a ser conservador. Mas é preciso enfatizar que, mesmo no caso dos pomares, não se verifica um aumento oportunístico em função da alta dos valores: o que predominou foi a invariância. Estamos, aqui, nos antípodas de um sistema de mercado em que os preços se impõem como medida universal e orientam o comportamento dos agentes econômicos. No sistema predominante em Larsa, a formação do valor certamente sinalizava aos vendedores as condições de realização da venda, mas a incorporação destes sinais era condicionada por outros princípios de racionalidade, em particular a preservação do patrimônio do grupo doméstico, que se traduzia por meio de um mecanismo de resistência à alienação.

Assim, do ponto de vista do funcionamento do sistema econômico, a moral doméstica - o conjunto de valores tradicionais que orientavam as práticas da unidade doméstica enquanto grupo - era um fator de desestímulo à expansão da base produtiva, ao menos no sentido da economia clássica: ${ }^{39}$ uma ampliação da demanda, tendo como manifestação mais imediata a alta dos preços, não garantia uma resposta equivalente no nível das ofertas de terras disponíveis no mercado. Os efeitos observados eram até mesmo inversos, pois a moral doméstica reagia às flutuações do valor a partir de um dispositivo mental particular, para o qual a conservação do patrimônio era prioritária. A simples indicação dos compradores de uma vontade de aquisição a preço majorado não era suficiente para assegurar as condições de negociação. Certamente, ao menos em muitos casos, as necessidades materiais impuseram a alienação do patrimônio familiar. No entanto, para compreender corretamente o comportamento de disposição, é preciso integrá-lo em um quadro mais amplo de valores e práticas costumeiras que insistiam sobre os efeitos nocivos da venda, que encorajavam a evitá-la e que, nos casos em que ela se tornava inevitável, prescreviam uma alienação tão parcial quanto possível. O resultado foi, enfim,

\footnotetext{
${ }^{39}$ Esta formulação deve sua inspiração à noção de "moral economy" de E. P. Thompson "The moral economy of the English crowd in the Eighteenth century", Past and Present, 50, 1971, p. 76-136. Uma avaliação do potencial da tese de Thompson no campo da assiriologia é feita em um artigo, infelizmente bastante confuso, por S. B. Murphy, "The notion of moral economy in the study of ancient Near East" in: J. Prosecky (ed.), Intellectual Life of the Ancient Near East. (43ème Rencontre Assyriologique Internationale). Prague, Academy of Sciences of the Czech Republic Oriental Institute, 1998, p. 269-281.
} 
um mercado de bens imóveis em que os estímulos da alta de preço não geravam forçosamente maior oferta dos bens em circulação. Em geral, foi o contrário que ocorreu. A descoberta destes movimentos, por vezes inesperados em face da nossa sensibilidade econômica moderna, obriga a reconsiderar certas idéias persistentes nas interpretações sobre a vida material da Baixa Mesopotâmia do início do segundo milênio.

\section{Abreviações}

HE - Tablete da École Pratique des Hautes Études (Paris).

PSBA - Proceedings of the Society of Biblical Archaeology (Londres).

RS - Rîm-Sîn.

SAOC - Studies in Ancient Oriental Civilization (Chicago).

TCL - Textes Cunéiformes du Louvre (Paris).

TLB - Tabulae Cuneiformes a F. M. Th. de Liagre Böhl Collectae (Leiden).

VS - Vorderasiatische Schriftdenkmäler (Berlin).

WS - Warad-Sîn.

YOS - Yale Oriental Series (Yale). 